
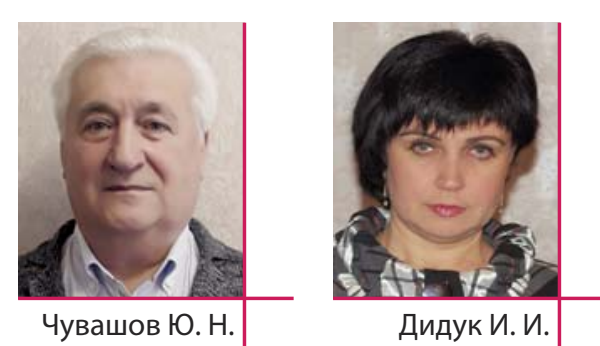

Дидук И. И.
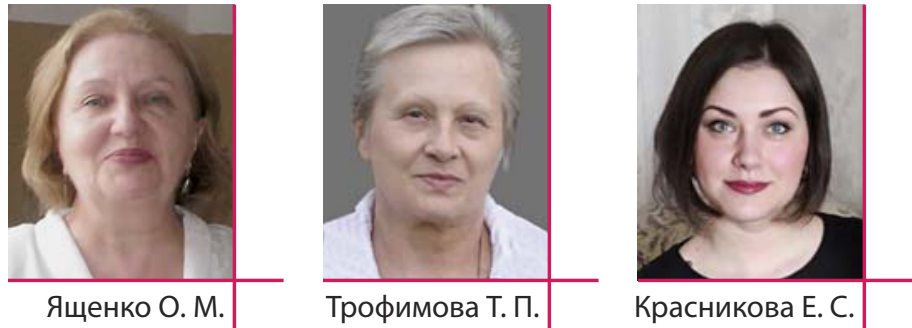

Красникова Е. С.
Чувашов Ю. М., к.Х.Н., директор ДП НТЦ «Базальтоволокнисті матеріали» ІПМ НАНУ; зав. лабораторії фізико-хімії силікатних систем і технології базальтових волокон ІПМ НАНУ

๙ +380445170963凶bavoma@ukr.net

Дідук І. І., зам.директора ДП НТЦ «Базальтоволокнисті матеріали» ІПМ НАНУ; ст.н.сп. лабораторії фізико-хімії силікатних систем і технології базальтових волокон ІПМ НАНУ

๘+380445170963凶bavoma@ukr.net

Ященко О. М., к.т.н., ст.н.сп. лабораторії фізико-хімії силікатних систем і технології базальтових волокон ІПМ НАНУ

\&+380445170963凶bavoma@ukr.net

Трофимова Т.П., пров. інж. лабораторії фізико-хімії силікатних систем і технології базальтових волокон ІПМ НАНУ

๙ +380445170963凶bavoma@ukr.net

Краснікова К. С., пров. інж. лабораторії фізико-хімії силікатних систем і технології базальтових волокон ІПМ НАНУ

\%+380445170963凶bavoma@ukr.net
Iurii Chuvashov, Director of State Enterprase «Scientific Technological Centre» Basalt-fiber materials «IPM NASU; Head of the laboratory of chemical-physical silicate systems and technology of basalt fibers IPM NASU s+380445170963凶bavoma@ukr.net

Iryna Diduk, Deputy director of State Enterprase « Scientific Technological Centre» Basalt-fiber materials «IPM NASU; Senior Researcher laboratory of chemical-physical silicate systems and technology of basalt fibers IPM NASU s+380445170963凶bavoma@ukr.net

Olga Jashctshcenko, Senior Researcher laboratory of chemical-physical silicate systems and technology of basalt fibers IPM NASU

s+380445170963凶bavoma@ukr.net

T. Trofimova, Senior Researcher laboratory of chemical-physical silicate systems and technology of basalt fibers IPM NASU

\& +380445170963凶bavoma@ukr.net

Ekaterina Krasnikova, Lead Engineer laboratory of chemical-physical silicate systems and technology of basalt fibers IPM NASU \&+380445170963凶bavoma@ukr.net

\title{
КОМПОЗИЦИОННЫЕ МАТЕРИАЛЫ НА ОСНОВЕ ВОЛОКНИСТЫХ КОМПОНЕНТОВ ИЗ ГОРНЫХ ПОРОД И ИХ ОТХОДОВ
}

\section{КОМПОЗИЦІЙНІ МАТЕРІАЛИ НА ОСНОВІ ВОЛОКНИСТИХ КОМПОНЕНТІВ З ГІРСЬКИХ ПОРІД ТА ЇХ ВІДХОДІВ COMPOSITE MATERIALS BASED ON FIBROUS COMPONENTS FROM ROCKS AND THEIR WASTE}

Аннотация. В работе показана возможность использования в цементных композициях волокнистых и чешуйчатых наполнителей из горных пород типа базальтов, силикатных отходов: некондиционных примесей, отходов от производства волокон из горных пород (типа «корольки»), чешуеобразных материалов, которые способны сохранять свои свойства в условиях твердения бетона в течение длительного времени для использования в отрасли дорожного строительства (тротуарная плита, перегородки, бордюры, причалы и т.д.).

Ключевые слова: горные породы, базальтовые волокна, чешуйчатый наполнитель, силикатные отходы, цементная композиция.

Анотація. В роботі показано можливість використання в цементних композиціях волокнистих і лускоподібних наповнювачів із гірських порід типу базальтів, силікатних відходів: некондиційних домішок, відходів виробництва базальтових волокон (типу «корольки»), лускоподібних матеріалів, здатних зберігати свої властивості в умовах твердіння бетону протягом тривалого часу для використання в галузі дорожнього будівництва (тротуарна плита, перегородки, бордюри, причали тощо)

Ключові слова: гірські породи, базальтові волокна, лускоподібний наповнювач, силікатні відходи, цементна композиція.

Annotation. The article shows the possibility of using in the cement compositions fibrous and scaly fillers from rocks such as basalts, silicate wastes: nonstandard impurities, waste from the production of fibers from rocks (of type «bead», such as «regulus»), scalable materials that are capable of retaining their properties under conditions of concrete hardening for a long time for use in the field of road construction (paving slab, partitions, curbs, pier, etc.).

Key words: rocks, basalt fibers, scaly filler, silicate waste, cement composition.

\section{Введение}

Развитие строительства покрытий различного функционального назначения требует расширения сырьевой базы, повышения качества и эффективности строительных изделий и конструкций. Широкое применение нашли наиболее эффективные строительные материалы - бетон и железобетон. Производство железобетона требует увеличения потребления арматурной стали. Но запасы железных руд во многих регионах ограничены, кроме того, сталь, предназначенная для изготовления строительных конструкций, легируются молибденом, никелем, вольфрамом, ванадием, кобальтом и др., Содержание которых в земной коре довольно небольшое и постоянно исчерпывается. В связи с этим экономия металла в строительстве является актуальной задачей.
Одним из способов решения этой проблемы является использование композиционных материалов, состоящих из двух основных компонентов: армирующего - стеклянных волокон (в том числе из горных пород) и связующего из неорганических вяжущих веществ - цемента.

Искусственные каменные материалы (бетоны), характеризуются низким сопротивлением на разрыв и образованием усадочных трещин при застывании. Ликвидировать образование трещин можно различными способами. В технологии цементов и бетонов нашли широкое применение различные виды волокон - стальная фибра, стекловолокно, фибра из полипропилена. Одной из первоначальных функций фибры является уменьшение микро- и макротрещин различной глубины, образующихся в результате усадки композитов, при- 
водящей к сокращению срока службы изделий. Известно, что прочность сцепления армирующего компонента и матрицы зависят от прочности контактного слоя цементного камня и интенсивности взаимодействия между компонентами композиции [1-4].

Результаты экспериментов подтверждают возможность использования непрерывных базальтовых волокон, а также и грубых волокон для армирования бетонных смесей в строительстве. Чем меньше диаметр базальтового волокна, тем больше снижение его прочности в цементной среде. Наиболее интенсивно это происходит на протяжении (3-6) месяцев. Самый высокий уровень потери прочности при армировании бетонов наблюдается в алюмоборосиликатных волокнах [1-5].

Деятельность разного рода производств (в том числе производящих волокна из горных пород) сопровождается образованием техногенных отходов. Техногенные скопления уменьшают земельные площади, загрязняют почву и окружающую среду, обостряют экологические проблемы.

Поэтому переработка и использование техногенных продуктов в производстве теплоизоляционных и строительных материалов способствует решению многих задач:

- улучшению экологической обстановки на объектах и регионах в целом;

- утилизации отходов;

- экономии энергетических и сырьевых ресурсов и т.п.

\section{Цель исследований}

Изучение возможности использования волокон диаметром болем 70 мкм, чешуеподобных материалов из горных пород и разного рода армирующих компонентов на основе силикатных отходов: некондиционных примесей, отходов от производства волокон из горных пород типа «корольки» в цементних композициях

\section{Объекты и методы исследований}

В качестве основных объектов исследований использованы композиции на основе портландцементного вяжущего, волокон из горных пород диаметром (70-700) мкм и волокнистых отходов, «королька» (измельченных волокон из горных пород), чешуйчатого материала. Дополнительно в состав формуемой смеси вводили до 10 \% молотых силикатосодержащих отходов (некондиционные, поврежденные бетонные и минераловатные материалы и изделия). Химический состав армирующих материалов приведен в таблице 1.

Определение микроструктуры образцов проводили на растровом электронном микроскопе TESLA-BS-
300. Для этого на поверхность образца размером 10 х 10 x 10 мм напыляли слой золота толщиной 20-30 нм.

В работе использованы классические методы исследования в соответствии с ГОСТ, ГСТУ, ТУ.

\section{Основная часть}

В отличие от железобетона и армоцемента, композиции с использованием базальтовых волокон и других силикатосодержащих наполнителей - композиционные материалы, где армирующие наполнители рассредоточены и равномерно распределены по всему сечению, благодаря чему достигается высокая прочность и трещиностойкость материалов. Цементное вяжущее придает композиции способность формироваться в изделия различных конфигурации и размеров. Использование неорганических связующих веществ и различных видов волокнистых наполнителей позволяет регулировать свойства композиционных материалов в широком диапазоне и получать материалы разного функционального назначения.

Одним из факторов, сдерживающих применение волокон из горных пород, является то, что они как и волокна из стекла подвержены коррозии в бетоне под влиянием щелочной среды при гидратации цемента, что приводит со временем к снижению их прочности.

Возможность равномерного распределения волокон в цементном растворе в значительной степени зависит от диаметра и длины волокон, а также от их соотношения, от объемного содержания волокон, размера частиц наполнителей и их количества, а также от способов смешивания.

Теоретически более длинные волокна и с большим отношением длины к диаметру лучше, чем более короткие. Однако длинные волокна более тяжело ввести в бетон и они неравномерно распределяются по объему. Поэтому представляет интерес исследование возможности использования коротковолокнистых базальтовых отходов в армировании бетонных материалов.

При разработке технологии получения волокнистых смесей на основе минеральных вяжущих установлено, что с увеличением длины волокнистого наполнителя и уменьшением его диаметра снижается легкость укладки композиций. Увеличение диаметра волокнистого наполнителя облегчает процесс смешивания.

В случае использования в качестве материала матрицы портландцемента, процесс взаимодействия волокнистого армирующего компонента, с новообразованиями твердеющего вяжущего обусловлен химическим взаи-

Виды и химический состав армирующих материалов

Таблица 1.

\begin{tabular}{|c|c|c|c|c|c|c|c|c|}
\hline \multirow{2}{*}{ Армирующий компонент } & \multicolumn{8}{|c|}{ Содержание оксидов, мас. \% } \\
\hline & $\mathrm{SiO}_{2}$ & $\mathrm{CaO}$ & $\mathbf{R}_{\mathbf{2}} \mathbf{O}$ & MgO & $\mathrm{Fe}_{2} \mathrm{O}_{3}+\mathrm{FeO}$ & $\mathrm{Al}_{2} \mathrm{O}_{3}$ & $\mathrm{TiO}_{2}$ & п.п.п \\
\hline $\begin{array}{c}\text { Волокно из горных пород, } \\
\text { Волокнистые отходы, «королек» }\end{array}$ & $49,71-52,20$ & $11,70-13,90$ & $1,80-2,03$ & $2,01-2,88$ & $12,51-14,89$ & $14,90-16,22$ & $0,3-0,7$ & $0,9-1,2$ \\
\hline Чешуйчатый наполнитель & $48,20-49,10$ & $8,10-8,31$ & $2,52-2,70$ & $4,80-5,20$ & $14,20-14,70$ & $14,50-14,70$ & $2,50-2,70$ & $0,90-1,11$ \\
\hline
\end{tabular}

Виды и химический состав армирующих материалов

\begin{tabular}{|c|c|c|}
\hline Толщина, мкм & \multicolumn{2}{|c|}{$1,8-4,5$} \\
\hline Размер частиц, мм & \multicolumn{2}{|c|}{$0,25-9,0$} \\
\hline Насыпная плотность, кГ// $\mathrm{M}^{3}$ & \multicolumn{2}{|c|}{$120-350$} \\
\hline \multirow{4}{*}{ Химическая стойкость, \%, В: } & $\mathrm{H} 2 \mathrm{O}$ & $97,5-99,5$ \\
\hline & $0,5 \mathrm{H} \mathrm{NaOH}$ & $77,0-97,3$ \\
\hline & $2,0 \mathrm{H} \mathrm{NaOH}$ & $52,0-86,2$ \\
\hline & $2,0 \mathrm{H} \mathrm{HCl}$ & $40,5-73,8$ \\
\hline
\end{tabular}


модействием $\mathrm{Ca}(\mathrm{OH})_{2}$ с поверхностью наполнителя и сопровождается снижением количества в составе новообразования свободной извести и увеличением количества гидросиликата.

Осуществлена попытка использования как составной части композиционных материалов силикатсодержащих отходов (некондиционные и поврежденные железобетонные изделия, материалы и изделия, срок реализации которых истек и полученные во время демонтажа жилых и производственных зданий).

Указанные отходы методом специальной обработки (с отделением арматурной стали) превращали в строительный щебенькрошку и использовали как крупнозернистый наполнитель для получения бетонных изделий (тротуарная плитка, бордюры и другие дорожные покрытия).

Для улучшения показателей прочности композиций и предоставления более привлекательного вида дополнительно вводили в состав формирующей смеси небольшое количество пыли из горных пород, молотые силикатосодержащие отходы и чешуйчатообразные материалы.

Использование вышеуказанных отходов и вторичных продуктов позволит в (2-3) раза снизить себестоимость готового материала.

Для разработки составов композиций формировали специальные кубики и брусочки на основе измельченных силикатосодержащих отходов, «королька», чешуйчатообразных материалов, волокон из горных пород и цементного или цементно-песчаного раствора (с добавлением модификаторов и без них).

Коррозионную стойкость волокнистых и чешуйчатых наполнителей определяли по их взаимодействию с насыщенным раствором $\mathrm{Ca}(\mathrm{OH})_{2}$, а также с жидкой фазой твердеющего портландцемента.

Исследование кинетики взаимодействия силикатных волокон с $\mathrm{Ca}(\mathrm{OH})_{2}$ определялась с помощью метода установления активности гидравлических примесей (фиксирующая характеристика - количество СаO, впитанная 1 г силикатных волокон).

Исследуемые волокна, находились в насыщенном растворе $\mathrm{Ca}(\mathrm{OH})_{2}$, на протяжении 9 месяцев.

На рис. 2 приведены результаты определения кинетики поглощения $\mathrm{CaO}$ силикатными наполнителями из насыщенного раствора $\mathrm{Ca}(\mathrm{OH})_{2}$.

Анализ результатов испытаний показывает, что исследуемые волокна, чешуеобразные материалы и «королек» характеризуются небольшим поглощением извести при длительном нахождении в насыщенном растворе $\mathrm{Ca}(\mathrm{OH})_{2}$.

В таблице 2 приведены результаты влияния синтетической жидкой фазы твердеющего портландцемента на корозионную стойкость волокон различного диаметра.

При нормальных условиях твердения эти волокна и волокнистые отходы, как и под влиянием синтетической жидкой фазы твердеющего портландцемента, с увеличением диаметра характеризуются увеличением уровня прочности в портландцементе $(98,1-99,9) \%$.

Об интенсивности взаимодействия наполнителей из горных пород с портландитом твердеющего цементного камня свидетельствуют результаты электронно-микроскопических исследований микроструктуры сформированных образцов (рисунки 4, 5).

Микроструктура композита на основе портландцемента и чешуйчатого материала представлена кристаллическими группами неправильной формы, которые срослись между собой. Поры вытянутой и округлой формы размером до 120 мкм (отдельные - до 500 мкм). Между отдельными порами наблюдаются перегородки толщиной до 5 мкм (рисунок 4).

Структура материала на основе портландцемента и наполнителя из горных пород (волокна и «королек») составлена из микрозернистых кристаллов неправильной формы, поризованная (рисунок 5). Размеры кристаллов (0,5-20) мкм. В больших порах наблюдаются новообразования значительно большего размера чем структура основного материала. Зона контакта между армирующими волокнами и материалом матрицы сплошная, только в отдельных местах есть разрывы, которые, очевидно, образовались в результате абразивного воздействия режущего тела при подготовке образцов к анализу.
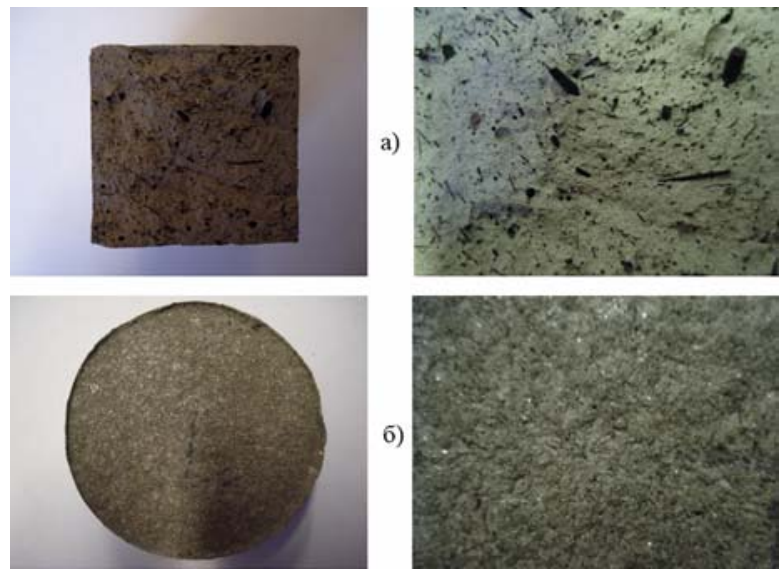

Рис. 1. Образцы композиционного материала на основе: а) волокон из горных пород и портландцементного связующего; б) чешуйчатого наполнителя и портландцементного связующего

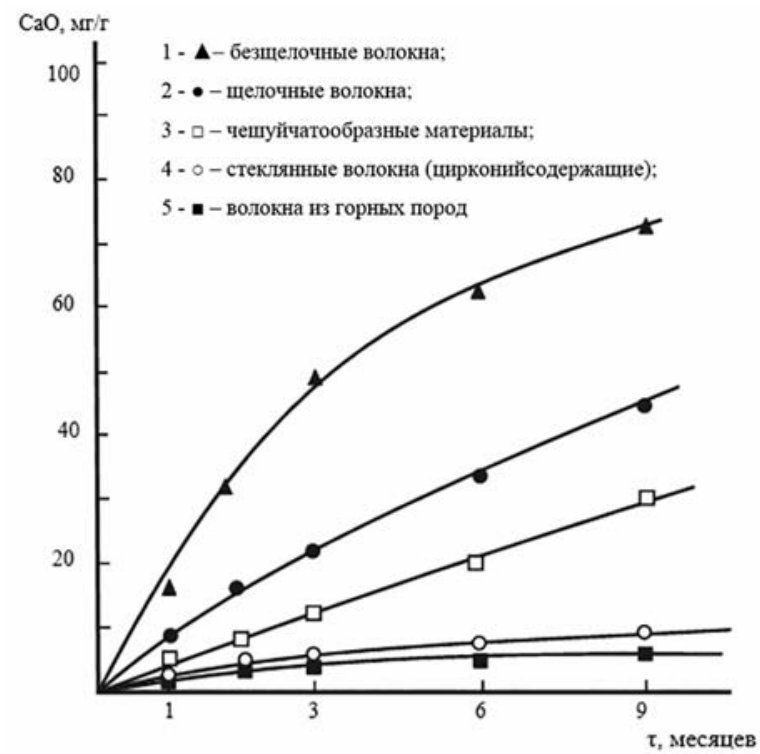

Рис. 2. Поглощение СаО силикатными волокнами из раствора $\mathrm{Ca}(\mathrm{OH})_{2}$

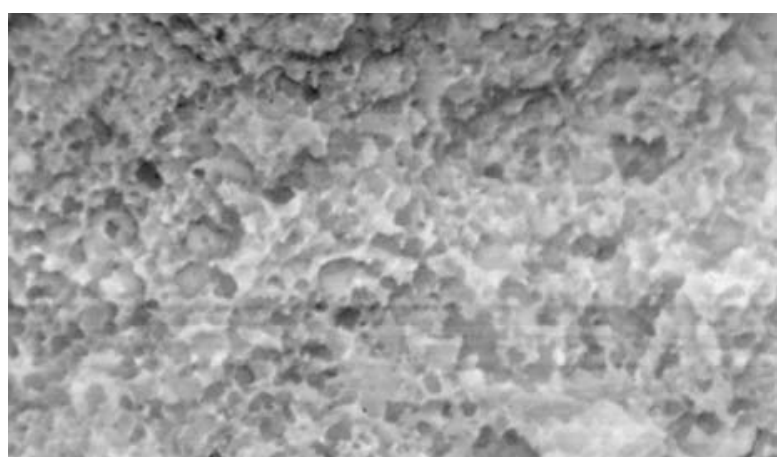

Рис. 4. Микроструктура композита

на основе портландцемента и чешуйчатого материала

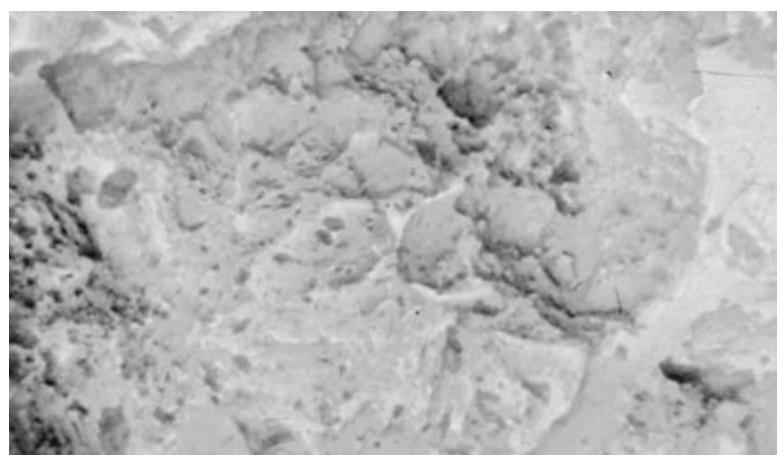

Рис. 5. Микроструктура композита на основе портландцемента и наполнителя из горных пород (волокна и «королек») 
Влияние синтетической жидкой фазы твердеющего портландцемента на прочность волокон

\begin{tabular}{|c|c|c|c|c|c|}
\hline \multirow{2}{*}{$\begin{array}{c}\text { Диаметр волокон, } \\
\text { мкм }\end{array}$} & \multirow{2}{*}{$\begin{array}{c}\text { Начальная проч- } \\
\text { ность, Кг/Mм² }\end{array}$} & \multicolumn{3}{|c|}{ Прочность волокон после выдерживания в смеси, кг/мм² } & \multirow{2}{*}{ 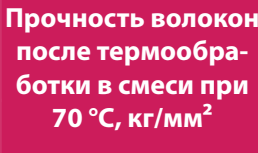 } \\
\hline & & 7 суток & 30 суток & 90 суток & \\
\hline $12-14$ & 137,0 & 127,5 & 96,5 & 73,7 & 75,2 \\
\hline $20-21$ & 87,8 & 85,3 & 76,5 & 69,4 & 71,1 \\
\hline $25-27$ & 49,3 & 48,6 & 48,7 & 47,5 & 41,0 \\
\hline $45-54$ & 27,0 & 26,8 & 26,6 & 26,3 & 23,7 \\
\hline $70-140$ & 21,2 & 21,0 & 20,1 & 19,0 & 18,3 \\
\hline $180-300$ & 18,0 & 18,0 & 17,8 & 17,6 & 16,9 \\
\hline $450-700$ & 14,2 & 14,0 & 14,2 & 14,9 & 14,0 \\
\hline
\end{tabular}

Таблица 3

Показатели прочности композитов на основе волокнистых, чешуйчатых наполнителей и отходов типа «королек»

\begin{tabular}{|c|c|c|c|c|}
\hline \multirow{2}{*}{ Тип наполнителей } & \multicolumn{4}{|c|}{ Прочность при изгибе, МПа за период } \\
\hline & 7 суток & 28 суток & 3 месяца & 6 месяцев \\
\hline Базальтовое волокно 180-250 мкм & 18 & 19,2 & 21,6 & 25,5 \\
\hline Чешуйчатый наполнитель & 7,2 & 7,0 & 8,1 & 9,0 \\
\hline «Королек» & 21 & 22,5 & 23,2 & 25,7 \\
\hline
\end{tabular}
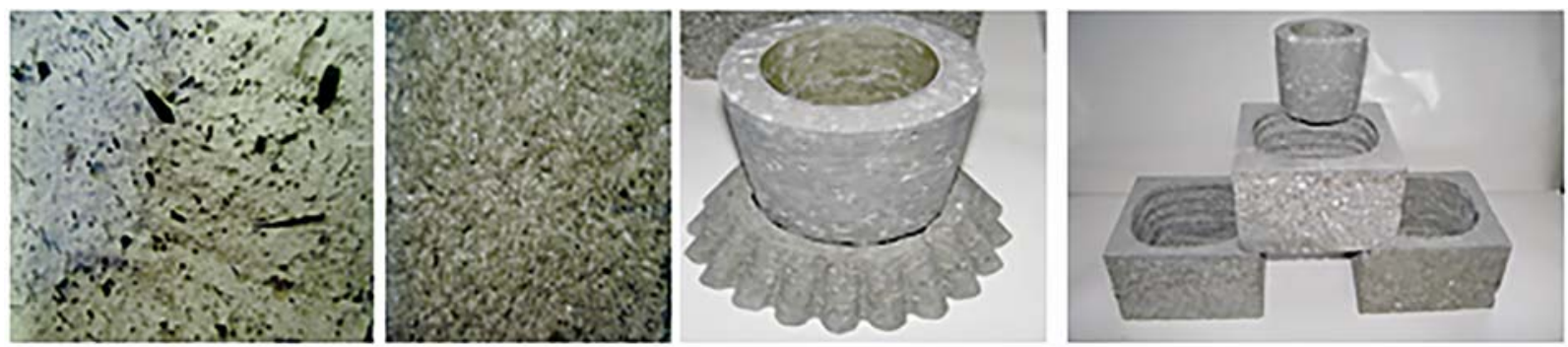

Рис. 6. Образцы полученных материалов на основе цементного вяжущего, чешуе-

волокнистых (силикатосодержащих отходов) наполнителей

Результаты исследования изменения прочности полученных композиций представлены в таблице 3.

Количество волокнистых и чешуйчатых наполнителей, введенных в цементную матрицу при объемно-произвольном армировании и обычном способе смешивания, находилось в пределах $(1-25) \%$.

На рисунке 6 представлены образцы полученных материалов.

\section{Заключение}

Проведенные исследования указывают на целесообразность использования волокнистых и чешуйчатых наполнителей из горных пород, силикатсодержащих отходов и неорганических вяжущих при изготовлении дисперсноармированных композиций для применения в области дорожного строительства (тротуарная плитка, поребрики, бордюры, пирсы и др.).

Сырьевая база эффективных строительных материалов может быть расширена за счет многотоннажных техногенных источников.

Использование вышеуказанных отходов и вторичных продуктов позволит в (2-3) раза снизить стоимость готовых материалов и улучшить экологическое состояние окружающей среды.
Литература:

1. Пащенко А.А., Сербин В.П. Армирование цементного камня. УкрНИИНТИ, Киев, 1977.

2. Глуховський В.В., Свідерський В.А., Ященко О.М. та ін. Композиційні матеріали на основі волокон з гірських порід та неорганічних в'яжучих. Київ - 2006.

3. Рабинович Ф.Н., Зуева В.Н., Макеева Л.В. Стойкость базальтовых волокон в среде гидратирующих цементов // Стекло и керамика. 2001.-№12. - С.12-14.

4. Д.В.Гербер Исследование влияния наномодифицированных волокон на свойства композиционных материалов с цементной матрицей // Успехи в химии и химической технологиию. - 2011. - Том XXV. - № 6 (122)

5. Чувашов Ю.М. Композиційні матеріали на основі наповнювачів з гірських порід та силікатовмістних відходів / Строительные материалы.- 2007. - №2. - С.41-44. 